\title{
53BP1 represses mitotic catastrophe in syncytia elicited by the HIV-1 envelope
}

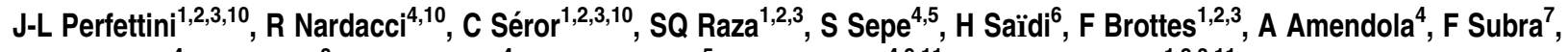 \\ F Del Nonno ${ }^{4}$, L Chessa ${ }^{8}$, A D'Incecco ${ }^{4}$, M-L Gougeon ${ }^{5}$, M Piacentini ${ }^{4,9,11}$ and G Kroemer ${ }^{*, 1,2,3,11}$
}

p53 binding protein-1 (53BP1) participates in checkpoint signaling during the DNA damage response (DDR) and during mitosis. In this study we report that 53BP1 aggregates in nuclear foci within syncytia elicited by the human immunodeficiency virus (HIV)-1 envelope. 53BP1 aggregation occurs as a consequence of nuclear fusion (karyogamy (KG)). It colocalizes partially with the promyelomonocytic leukemia protein (PML), and the ataxia telangiectasia mutated kinase (ATM), the two components of the DDR that mediate apoptosis induced by the HIV-1 envelope. ATM-dependent phosphorylation of 53BP1 on serines 25 and 1778 (53BP1S25P and 53BP1S1778P) occurs at these DNA damage foci. 53BP1S25P was also detected in syncytia present in the lymph nodes or frontal brain sections from HIV-1-infected carriers, as well as in peripheral blood mononucleated cells from HIV1-infected individuals, correlating with viral load. Knockdown of 53BP1 caused HIV-1 envelope-induced syncytia to enter abnormal mitoses, leading to their selective destruction through mitochondrion-dependent and caspase-dependent pathways. In conclusion, depletion of 53BP1 triggers the demise of HIV-1-elicited syncytia through mitotic catastrophe.

Cell Death and Differentiation (2010) 17, 811-820; doi:10.1038/cdd.2009.159; published online 30 October 2009

The envelope glycoprotein complex (Env) of human immunodeficiency virus-1 (HIV-1) can induce apoptosis by multiple mechanisms. ${ }^{1}$ A soluble Env derivative, gp120, kills cells through signals that are transmitted by chemokine receptors such as CXCR4. ${ }^{2-4}$ Cell surface-bound Env (composed by gp120 and gp41), which is present on the plasma membrane of HIV-1-infected cells, kills uninfected bystander cells expressing CD4 and CXCR4 (or similar chemokine receptors, depending on the Env variant) by several distinct mechanisms. First, transient interactions involving the exchange of lipids between the two interacting cells ('the kiss of death') without cell fusion may lead to the death of CD4-expressing target cells. Second, fusion of the interacting cells may initiate the formation of syncytia, which then succumb to apoptosis in a complex signaling pathway involving the activation of multiple kinases (ataxia teleangiectasia mutated (ATM), cyclin-dependent kinase-1 (Cdk1), checkpoint kinase-2 (Chk2), mammalian target of rapamycin (mTOR), p38 mitogen-activated protein kinase (p38 MAPK) and inhibitor of NF- $\kappa$ B kinase, $(\mathrm{IKK})),{ }^{5-9}$ as well as the activation of several transcription factors (NF- $\kappa \mathrm{B}$ and $\mathrm{p53}$ ), ${ }^{2,10}$ finally resulting in the activation of the mitochondrial pathway of apoptosis. ${ }^{11,12}$ These lethal signal transducers have been detected in the tissues of patients, within syncytia that are formed in the lymphatic tissues and the brain from HIV-1 carriers. At the apex of this apoptotic pathway, a DNA damage response (DDR) is triggered. After fusion of Env-exposing and uninfected cells, the nuclei contained in the common cytoplasm first remain separated and then fuse. The nonphysiological juxtaposition of non-synchronized genomes then triggers a DDR that involves the aggregation of the promyelocytic leukemia protein (PML) and the subsequent

\footnotetext{
${ }^{1}$ INSERM U848, 39 rue Camille-Desmoulins, F-94805 Villejuif, France; ${ }^{2}$ Institut Gustave Roussy, 39 rue Camille-Desmoulins, 94805 Villejuif, France; ${ }^{3}$ Université Paris Sud - Paris 11, 39 rue Camille-Desmoulins, 94805 Villejuif, France; ${ }^{4}$ National Institute for Infectious Diseases 'Lazzaro Spallanzani', Via Portuense 292,00149 Rome, Italy; ${ }^{5}$ Department of Biology, University of Rome 'Roma Tre', Viale G Marconi 446, 00146, Rome, Italy; ${ }^{6}$ Institut Pasteur, Antiviral Immunity, Biotherapy and Vaccine Unit, Department of Infection and Epidemiology, 28 rue du Dr Roux, 75724 Paris Cedex 15, France; ${ }^{7}$ CNRS UMR 8113 LBPA, Ecole Normale Supérieure de Cachan, 61 avenue du Président Wilson, 94230 Cachan, France; ${ }^{8}$ II Faculty of Medicine, University of Rome 'La Sapienza', Rome, Italy and ${ }^{9}$ Department of Biology, University of Rome 'Tor Vergata', Via della Ricerca Scientifica 1, 00173, Rome, Italy

${ }^{*}$ Corresponding author: G Kroemer, INSERM U848, Institut Gustave Roussy, Pavillon de Recherche 1, 39 rue Camille-Desmoulins, F-94805 Villejuif, France.

Tel: 331421160 46; Fax: 331421160 47; E-mail: kroemer@orange.fr

${ }^{10}$ These authors contributed equally to this work.

${ }^{11}$ These authors share senior co-authorship.

Keywords: AIDS; apoptosis; DNA damage response; ATM; PML

Abbreviations: AIDS, acquired immunodeficiency syndrome; A-T, ataxia telangiectasia; ATM, ataxia telangiectasia mutated; ATMS1981P, ATM phosphorylated on serine 1981; Chk2, checkpoint kinase-2; Cdk1, cyclin-dependent kinase 1; CENP-E, centromere protein E; Cyto. $C$, cytochrome $C$; DDR, DNA damage response; DN, dominant negative; Env, envelope glycoprotein complex; GAPDH, glyceraldehyde phosphate dehydrogenase; HAART, highly active anti-retroviral therapy; $\gamma$-H2AX, phosphorylated histone 2AX; HAE, HIV-1-associated encephalitis; HIV-1, human immunodeficiency virus-1; IKK, inhibitor of NF- $\kappa$ B kinase; IKSR, inhibitor of NF- $\kappa$ B super repressor; KG, karyogamy; MAPK, mitogen-activated protein kinase; mTOR, mammalian target of rapamycin; NBS1, Nijmegen breakage syndrome-1; N9-Olo, N9-isopropyl-olomoucine; p38 MAPK, p38 mitogen-activated protein kinase; 53BP1, p53 binding protein 1; PBMC, peripheral blood mononuclear cells; PML, promyelomonocytic leukemia; Pre-KG, pre-karyogamy; SC, single cell; siRNA, small interfering RNA; Syn, syncytia; TopBP1, topoisomerase II $\beta$-binding protein 1; Vpr, viral protein R; Z-VAD-fmk, $N$-benzyloxycarbonyl-Val-Ala-Asp-fluoromethylketone

Received 17.8.09; accepted 11.9.09; Edited by RA Knight; published online 30.10.09
} 
ATM-mediated phosphorylation of histone H2AX $(\gamma-\mathrm{H} 2 \mathrm{AX}){ }^{8,13}$ PML, ATM and other DNA damage-relevant proteins (such as Nijmegen breakage syndrome-1 (NBS1)) are strictly required for syncytial apoptosis induced by HIV-1, suggesting that the DDR has a major role in acquired immunodeficiency syndrome (AIDS) pathogenesis.

The tumor suppressor protein, p53 binding protein-1 (53BP1) is a BRCA1 carboxy terminal (BRCT) repeat protein that has an important role in the DDR. Originally described as 53BP1, it is currently considered as a major initiator of DNA damage signaling and/or repair. ${ }^{14-18}$ Normally diffusely distributed through the nucleus during interphase, 53BP1 is recruited to sites of DNA lesions upon DDR ${ }^{19,20}$ in which it interacts with DNA double-strand breaks and many proteins involved in DNA damage, repair and checkpoint signaling, including BRCA1, Rad51, Mre11/Rad50/NBS1, ATM and $\gamma-\mathrm{H} 2 \mathrm{AX}$, to constitute DNA damage-inducible foci. ${ }^{15,21-23}$ Upon DDR, 53BP1 becomes hyper-phosphorylated (on serines 25 and 1778) in an ATM-dependent manner. ${ }^{24-26}$ 53BP1 is also phosphorylated during mitosis and participates in mitotic checkpoint signaling through its interaction with centromere protein $E$ (CENP-E) to kinetochores of chromosomes. ${ }^{27}$ Thus, 53BP1 is a molecular component of DNA damage response machinery, as well as of the mitotic machinery.

Driven by the premises that the DDR dictates syncytial cell death and that 53BP1 is one of the major DDR regulators, we decided to analyze the role of 53BP1 in HIV-1 Env-elicited apoptosis. In this study we report that 53BP1 is recruited to DNA damage foci within syncytia and undergoes ATMdependent activating phosphorylations. In sharp contrast with other DDR elements that are positive regulators of HIV-1 envelope-induced apoptosis, we found that 53BP1 acts as a negative regulator, meaning that its depletion enhances syncytial demise through mitotic catastrophe.

\section{Results and Discussion}

Aggregation of 53BP1 in DNA damage foci from karyogamic syncytia. HeLa cells, stably transduced with the lymphotropic HIV-1 ${ }^{\text {LAI }}$ envelope, form syncytia when they are cocultured with HeLa cells that express CD4 and CXCR4. ${ }^{11,28}$ Using this well-established system, we studied the effect of syncytium formation on the subcellular redistribution of 53BP1. At $48 \mathrm{~h}$ after coculture, we observed that 53BP1 (which is usually diffuse) ${ }^{21}$ was enriched in discrete spots that colocalized in DNA damage foci with $\gamma-\mathrm{H} 2 \mathrm{AX}$, as determined using two-color immunofluorescence (Figure 1a). At least part of this $\gamma-\mathrm{H} 2 \mathrm{AX}$-associated 53BP1 protein showed activating phosphorylations on serines 25 (Figure 1b, Supplementary Figure 1a) and 1778 (Figure 1c, Supplementary Figure 1b). Furthermore, 53BP1 (Figure 1d, Supplementary Figure 2a) and its phosphorylated forms (Figures 1e and f) colocalized partially with PML bodies. This partial colocalization concerned the strongly DNA-associated fraction of p53BP1 and PML that resisted in situ extraction with non-ionic detergents (Supplementary Figure 2b). Phosphorylated (and bonafide activated) ATM showed a relatively diffuse staining pattern that, however, colocalized in part with phosphorylated 53BP1 (Figures $1 \mathrm{~g}$ and $\mathrm{h}$ ). All these changes, including 53BP1 aggregation, affected a similar percentage of syncytia in a time-dependent manner (Figure 1i). A close inspection of the nuclear morphology revealed that the nuclei from freshly formed syncytia (which have undergone cytoplasmic fusion, cytogamy and do not yet show nuclear fusion, karyogamy $(\mathrm{KG})$ ) are free from PML aggregates and 53BP1 ${ }^{+}$DNA damage foci. Only when several nuclei within the same cell fuse, these features manifest until the cells succumb to apoptosis (Figure 1j).

Karyogamy can be inhibited by blocking Cdk1 with roscovitin or a dominant-negative (DN) Cdk1 mutant. This manipulation fully abolished p53BP1 aggregation and phosphorylation at the same time that it avoided the formation of $\gamma-\mathrm{H}_{2} \mathrm{AX}{ }^{+}$DNA damage foci (Figures 2a-c). Additional manipulations that result in the suppression of $K G$, such as inhibition of mTOR with rapamycin (Figure $2 b$ ) or suppression of $\mathrm{NF}-\kappa \mathrm{B}$ with a non-phosphorylable inhibitor of $\mathrm{NF}-\kappa \mathrm{B}$ (the 'inhibitor of NF- $\kappa \mathrm{B}$ super repressor' (IKSR), Figure $2 \mathrm{c}$ ), also reduced p53BP1 aggregation and phosphorylation. In contrast, inhibition of p38 MAPK (pharmacologically with SB203580 or genetically with a DN mutant), p53 (with the chemical inhibitor pifithrin- $\alpha$ or DN p53) or caspases (with the broad-spectrum inhibitor $N$-benzyloxycarbonyl-ValAla-Asp-fluoromethylketone (Z-VAD-fmk) or the Baculovirusderived inhibitor of apoptosis protein p35) failed to avoid $K G$, as well as 53BP1 aggregation and phosphorylation, although these manipulations strongly inhibited apoptosis (Figures $2 b$ and c). We conclude that the HIV-1 Env-elicited aggregation of phosphorylated 53BP1 depends on KG but not on apoptosis and that this 53BP1 aggregation is connected to the DDR.

Activating phosphorylation of 53BP1 by ATM. Given that aggregated, phosphorylated 53BP1 colocalizes partially with PML and phospho-ATM (Figure 1), we wondered whether these upstream effectors of the syncytial cell death pathway ${ }^{8,13}$ would be required for the aggregation of 53BP1. The knockdown of both PML and ATM abolished the formation of $\gamma-\mathrm{H}_{2} \mathrm{AX}{ }^{+}$foci, yet failed to affect the aggregation of 53BP1 in karyogamic nuclei (Figures 3a and $b)$. In accordance with published data showing that ATM can phosphorylate 53BP1 on serines $25^{29}$ and $1778,{ }^{26,30}$ we observed that the knockdown of ATM suppressed the phosphorylation of 53BP1. This result could be corroborated in a completely different experimental system in which primary $\mathrm{T}$ lymphoblasts (obtained by stimulation of circulating $\mathrm{T}$ lymphocytes with phytohemagglutinin and recombinant human interleukin-2) from patients with ataxia teleangiectasia (A-T, which are homozygous for inactivating mutations of the atm gene) and age- and sex-matched healthy volunteers were infected with HIV-1 ${ }^{\text {LAI }}$. In HIV-1elicited syncytia from controls, 53BP1 was phosphorylated on serine 25, and this phosphorylation was strongly reduced in syncytia from A-T patients (Figures $3 d$ and $e$ ). Altogether, these results indicate that ATM is required for the phosphorylation of 53BP1 but dispensable for its aggregation within the nuclei of karyogamic syncytia elicited by HIV-1. 
a

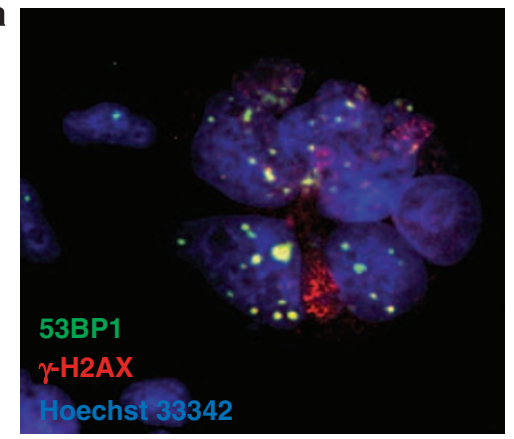

$25 \mu \mathrm{m}$

d

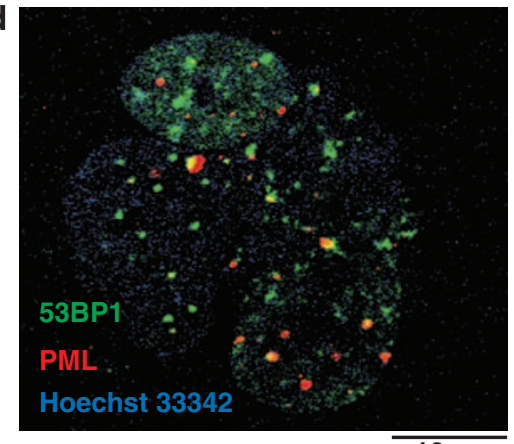

$10 \mu \mathrm{m}$

g

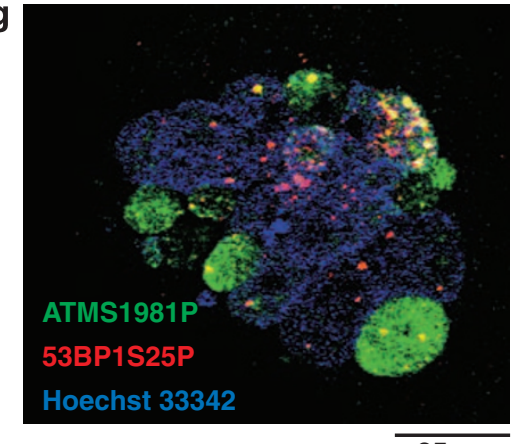

$25 \mu \mathrm{m}$

h

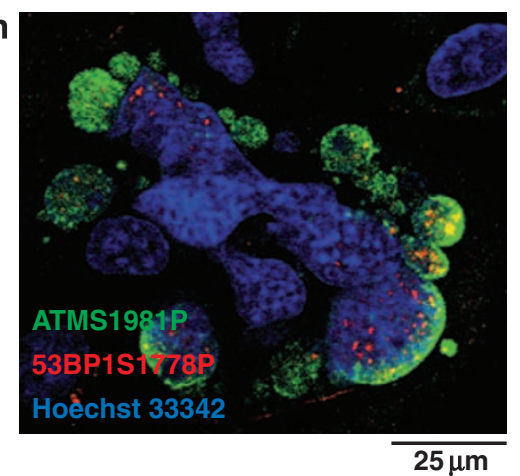

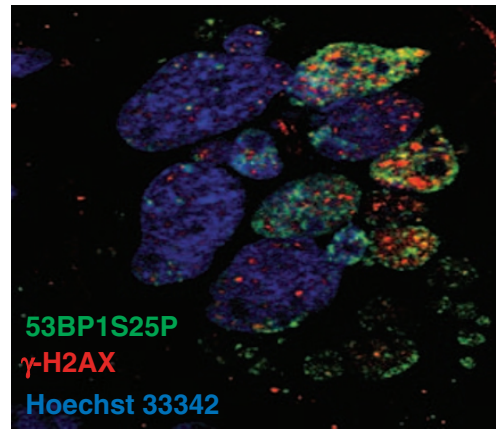

$25 \mu \mathrm{m}$

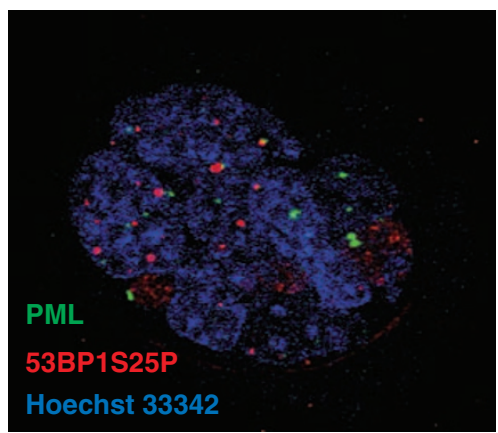

$25 \mu \mathrm{m}$
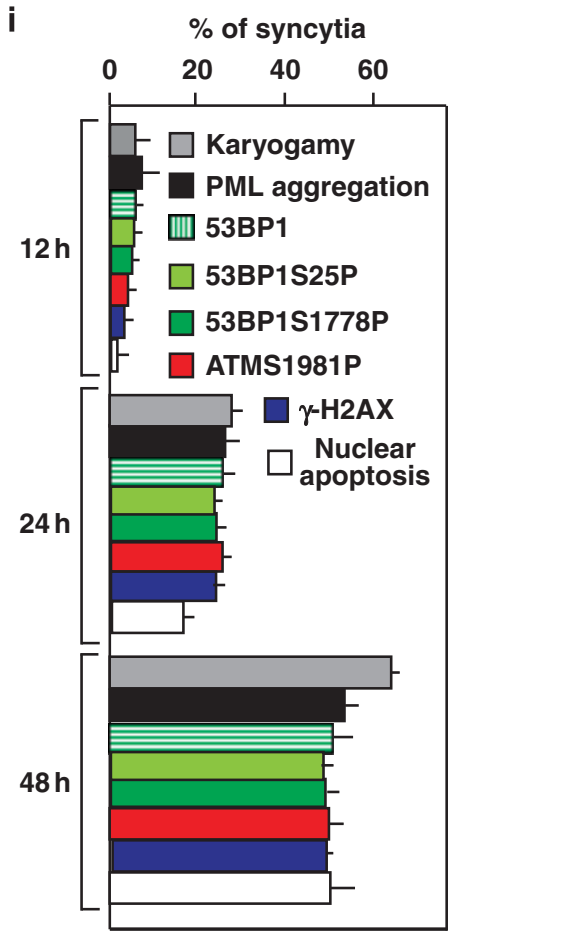

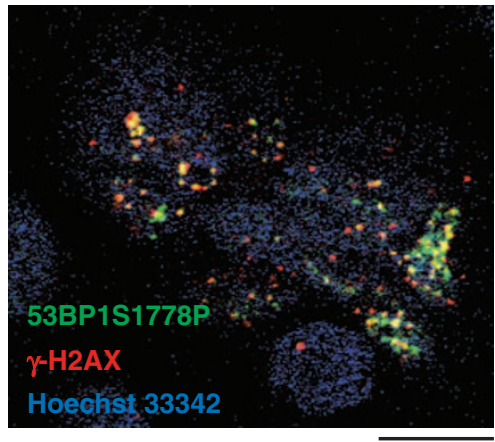

$25 \mu \mathrm{m}$

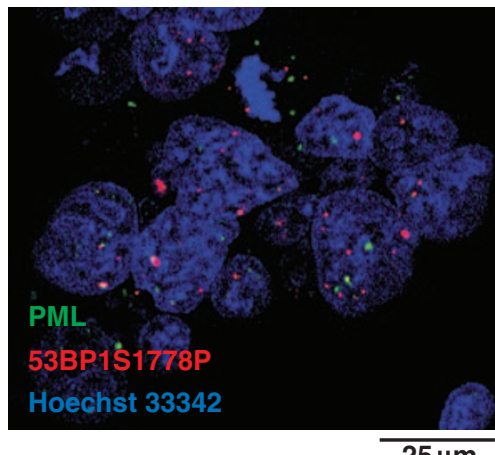

$25 \mu \mathrm{m}$

j
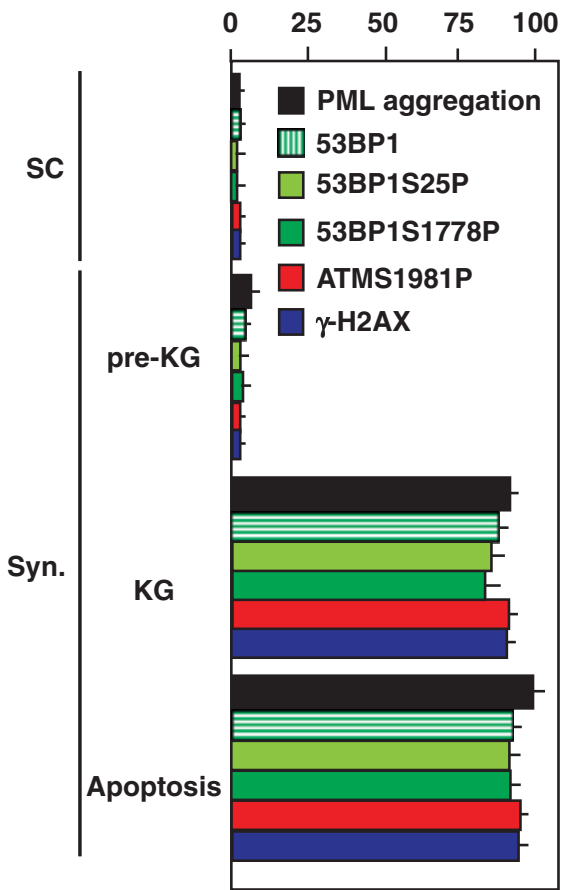

Figure 1 Aggregation and phosphorylations of 53BP1 in karyogamic syncytia elicited by HIV-1 Env. (a-h) Syncytia, arising from the coculture of HeLa Env and HeLa CD4 cells for $48 \mathrm{~h}$, were subjected to immunofluorescence stainings. Representative karyogamic syncytia stained with anti-53BP1, 53BP1S25P, 53BPS1778P, PML, ATMS1981P, $\gamma$-H2AX antibodies and Hoechst 33342 are shown. Colocalization between 53BP1(a, d), 53BP1S25P (b, e, g) and 53BP1S1778P (c, f, h) with $\gamma$-H2AX (a, b, c), PML (d, e, f) or ATMS1981P $(\mathbf{g}, \mathbf{h})$ are observed. (i) Kinetics of karyogamy (KG), of PML or of 53BP1 aggregation, of phosphorylations on serine 25 (53BP1S25P) or on serine 1778 of 53BP1 (53BP1S1778P), on serine 1981 of ATM (ATMS1981P) of H2AX, on serine 137 of H2AX (g-H2AX) and on nuclear apoptosis. (j) Quantification of PML or 53BP1 aggregation or phosphorylation of 53BP1 (53BP1S25P and 53BP1S1778P), ATM (ATMS1981P) and g-H2AX on single cells (SC), on prekaryogamic (pre-KG) and karyogamic (KG) syncytia and during apoptosis. Karyogamy and nuclear apoptosis are evaluated using Hoechst 33342 staining $(X \pm$ S.D., $n=3)$ 


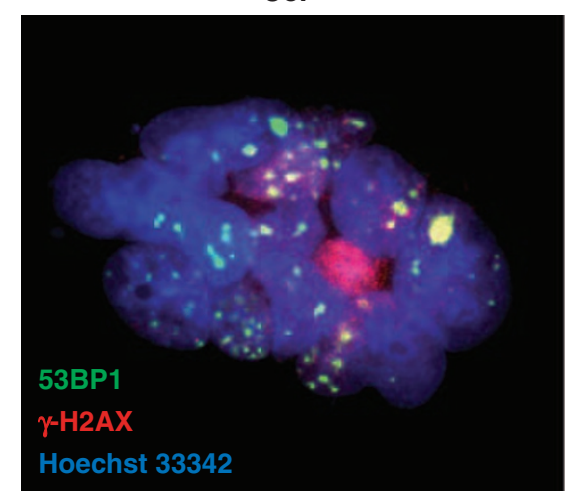

Roscovitin

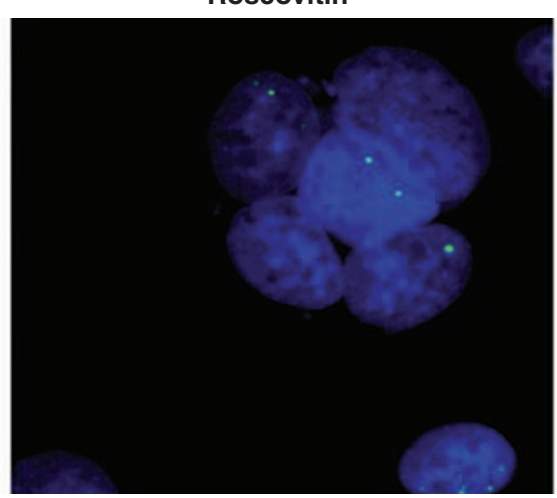

Z-VAD-fmk

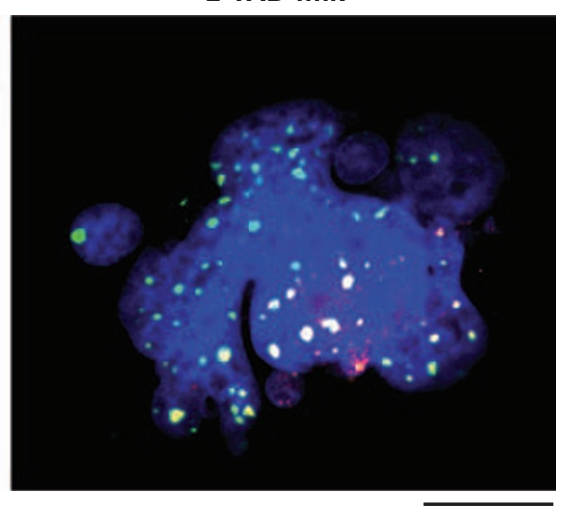

$10 \mu \mathrm{m}$
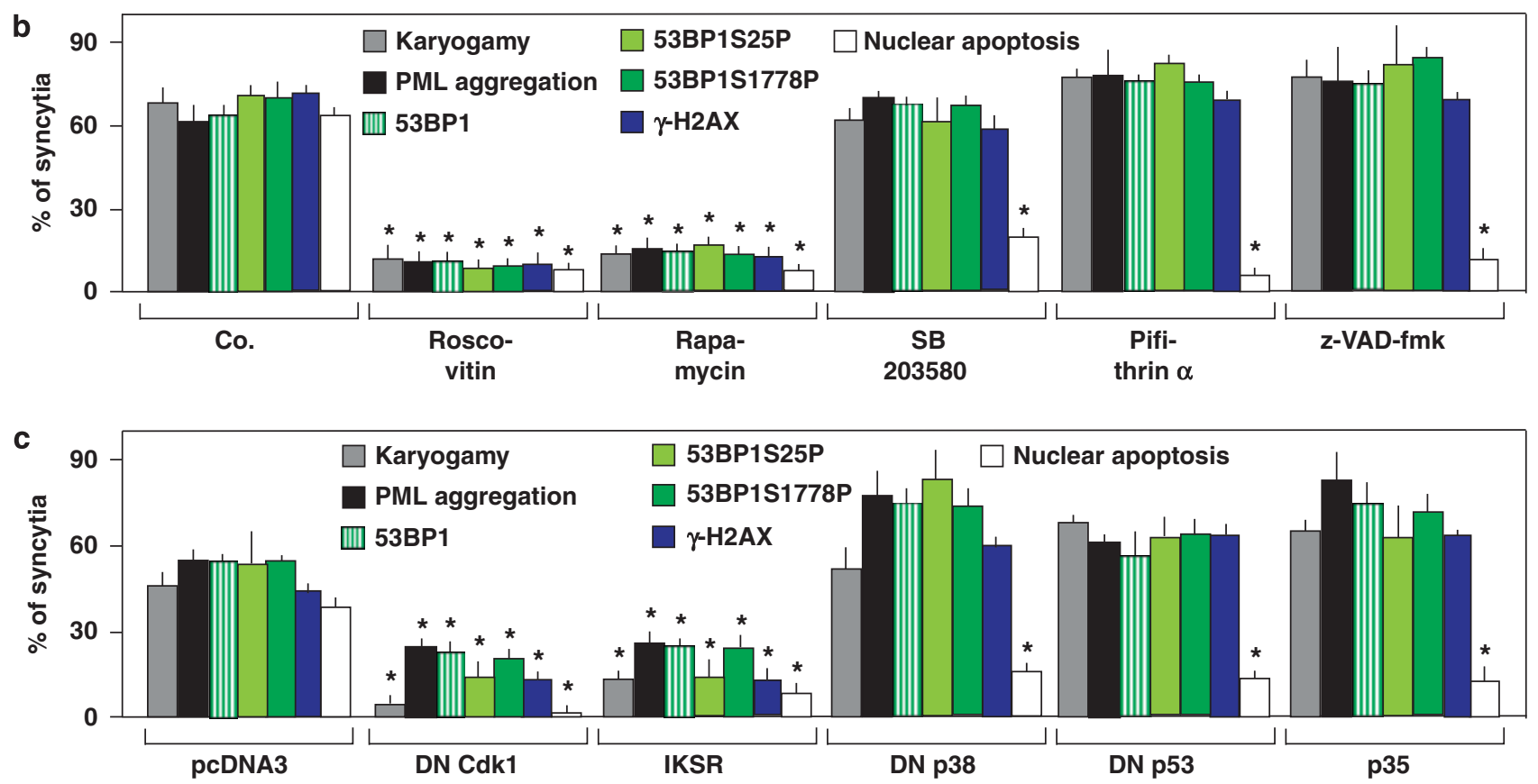

Figure 2 Aggregation and phosphorylations of 53BP1 occur after karyogamy (KG) but before the induction of the proapoptotic signal transduction pathway. Syncytia arising from the coculture of HeLa Env with HeLa CD4 cells were exposed to pharmacological and genetic inhibitors of karyogamy (roscovitin, rapamycin, DN Cdk1 and IKSR) or of syncytial apoptosis (SB203580, pifithrin- $\alpha$, Z-VAD-fmk, DN p38, DN p53 and p35) and were then stained with antibodies against 53BP1 and $\gamma$-H2AX. Karyogamy and nuclear apoptosis were determined using Hoechst 33342 staining. (a) Representative karyogamic syncytia untreated or treated with $1 \mu \mathrm{M}$ roscovitin or with $100 \mu \mathrm{M}$ of Z-VADfmk are shown. Note the loss of 53BP1 aggregation and of $\gamma-\mathrm{H} 2 \mathrm{AX}$-positive foci formation when cells are treated with $1 \mu \mathrm{M}$ roscovitin. (b, c) Effects of karyogamic and syncytial apoptosis inhibitors on 53BP1 aggregation and on its phosphorylation. The frequency of treated or transfected syncytia showing karyogamy, PML or 53BP1 aggregations, phosphorylation of 53BP1 on serine 25 (53BP1S25P) or on serine 1778 (53BP1S1778P), $\gamma-\mathrm{H} 2 \mathrm{AX}$ and nuclear apoptosis were determined as detailed in Materials and Methods $\left(X \pm S . D ., n=3\right.$, Student's $t$-test, $\left.{ }^{*} P<0.01\right)$

53BP1 depletion triggers mitotic catastrophe of syncytia. The depletion or inhibition of PML and ATM prevents syncytial apoptosis. 8,13 We therefore analyzed whether the depletion of 53BP1 by two different small interfering RNAs (siRNAs, Figure 4a) would have similar cytoprotective effects. The knockdown of 53BP1 failed to affect the frequency of $K G$ and had no inhibitory effects on the aggregation of PML or the formation of $\gamma-\mathrm{H} 2 \mathrm{AX}{ }^{+}$foci (Figures $4 \mathrm{~b}$ and $\mathrm{c}$ ). Unexpectedly, 53BP1 depletion resulted in an increase in apoptotic events, as measured by two different methods. First, 53BP1 knockdown resulted in an increased frequency of cells that failed to retain cytochrome $c$ (Cyto. $c$ ) in mitochondria (see the speckled distribution of Cyto. $c$ in cytoplasmic dots in control cells) and hence showed a diffuse, cytosolic distribution of immunofluorescence-detectable Cyto. $c$, correlating with the activation of caspase-3 (Figures $4 \mathrm{~b}$ and $\mathrm{c}$ ). Second, 53BP1 depletion caused an increase in the frequency of cells with Hoechst 33342-detectable chromatin condensation, which defines nuclear apoptosis (Figures $4 b$ and $c$ ). We also observed that 53BP1-depleted syncytia showed an abnormally high frequency of mitoses (Figure 4c), suggesting that mitotic catastrophe might explain the increased frequency of apoptotic events. 53BP1 reportedly behaves 
a

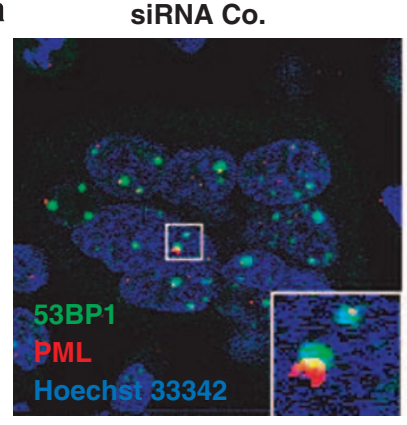

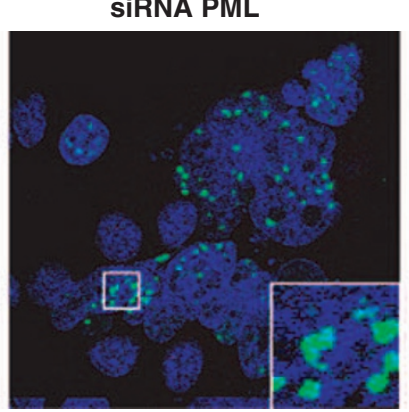

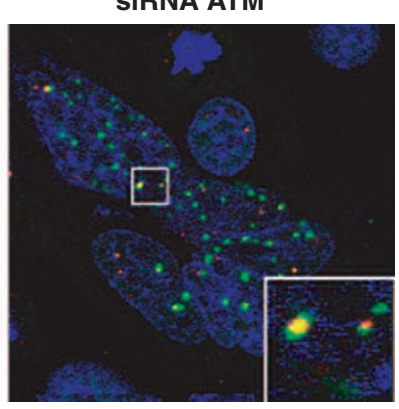

b

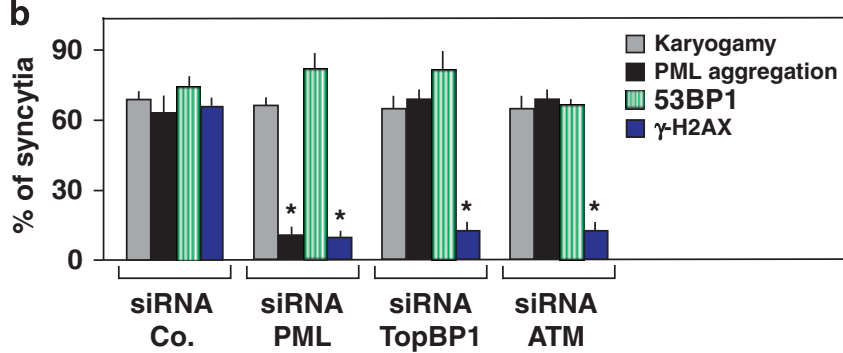

d
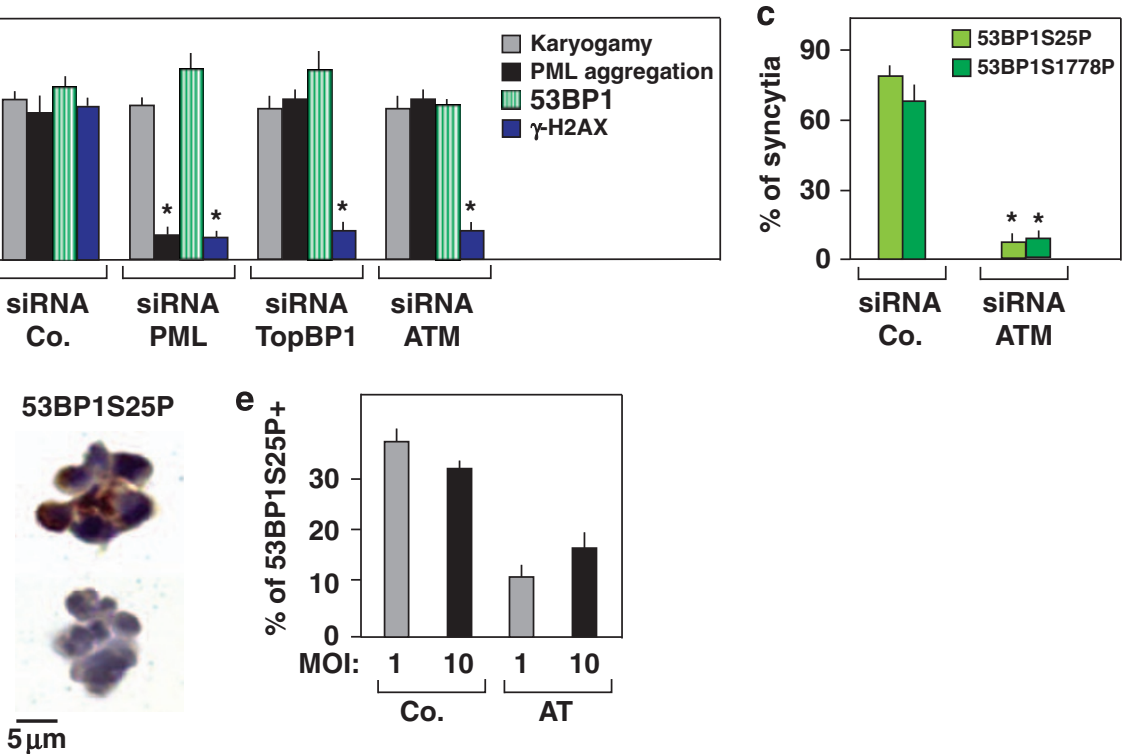

Co.

$5 \mu \mathrm{m}$

Figure 3 ATM controls 53BP1 phosphorylations but not its aggregation. (a, b) 53BP1 aggregation occurs before the activation of PML, TopBP1 and ATM. HeLa CD4 and HeLa Env cells were transfected $48 \mathrm{~h}$ before fusion with siRNAs specific for PML, TopBP1 and ATM and then were cocultured for $36 \mathrm{~h}$. Syncytia were then subjected to immunofluorescence microscopy for the detection of karyogamy (KG), apoptosis (nuclear chromatin condensation), $\gamma$-H2AX foci or the aggregation of PML and 53BP1. Representative karyogamic syncytia are shown after staining with antibodies against PML and 53BP1 (a). Results are shown as means \pm S.D. of three independent experiments (b). (c) ATM-dependent 53BP1 phosphorylation. After $48 \mathrm{~h}$ transfection with specific siRNA against ATM, HeLa CD4 and HeLa Env cells were cocultured for $36 \mathrm{~h}$ and stained with specific antibodies against 53BP1S25P and 53BP1S1778P. The effect of ATM knockdown on 53BP1 phosphorylation was evaluated using immunofluorescence microscopy in four independent experiments (X \pm S.D.). (d, e) Partial inhibition of 53BP1S25P on syncytia obtained after HIV-1 infection of PHA/L-2 lymphoblasts obtained from A-T patients. PHA/L-2 lymphoblasts from controls or A-T patients $(n=3)$ were infected by HIV-1, and the frequency of syncytia with 53BP1S25P ${ }^{+}$ nuclei was assessed. Representative syncytia are shown in $\mathbf{d}$ and quantitative data $(X \pm S . D ., n=3)$ are reported in $\mathbf{e}$. Two different multiplicities of infection of HIV-1 were used to determine the effects of ATM on syncytial 53BP1S25P (X \pm S.D., $n=3$ )

as a passenger protein and transiently associates with kinetochores during the metaphase. ${ }^{27}$ We also found that phosphorylated 53BP1 could associate with the contractile ring and midbody in normal mitoses of HeLa cells (Figure 5a), underscoring its probable implication in the control of mitosis. Indeed, the knockdown of 53BP1 from cocultured HeLa CD4 and HeLa Env cells increased the frequency of syncytia with abnormal, multipolar metaphases with multiple centrosomes that finally resulted in apoptotic chromatin condensation (Figures $5 b-d$ ). To firmly establish a link between the cell-cycle advancement and apoptotic demise of 53BP1-depleted cells, we blocked mitosis with N9-isopropyl-olomoucine (N9-Olo) and analyzed whether this treatment would antagonize the acceleration of syncytial apoptosis by 53BP1. Indeed, mitotic blockade prevented the increase in the mortality of syncytia induced by $53 \mathrm{BP} 1$ depletion (Figure $5 \mathrm{e}$ ), firmly establishing that 53BP1 acts as a repressor of mitotic catastrophe.

\section{BP1 aggregation and phosphorylation in tissues from} HIV-1-infected patients. Given the effect of 53BP1 on HIV-1 Env-elicited apoptosis, we wondered whether 53BP1 might be activated in tissues from HIV-1 carriers. Phospho53BP1 was detectable, within the frontal cortex, in the nuclei from giant multinuclear cells that are pathognomonic for HIV-associated encephalitis (Figure 6a). Phospho-53BP1 was also detectable within the sporadic syncytia present in lymph nodes from HIV-1 carriers (Figure 6b). In addition, a sizeable fraction of peripheral blood mononuclear cells (PBMC) from untreated HIV-1 carriers stained positively for phospho-53BP1 (Figure 6c), correlating with viral load (Figure 6d). Upon highly active anti-retroviral therapy (HAART), 
a
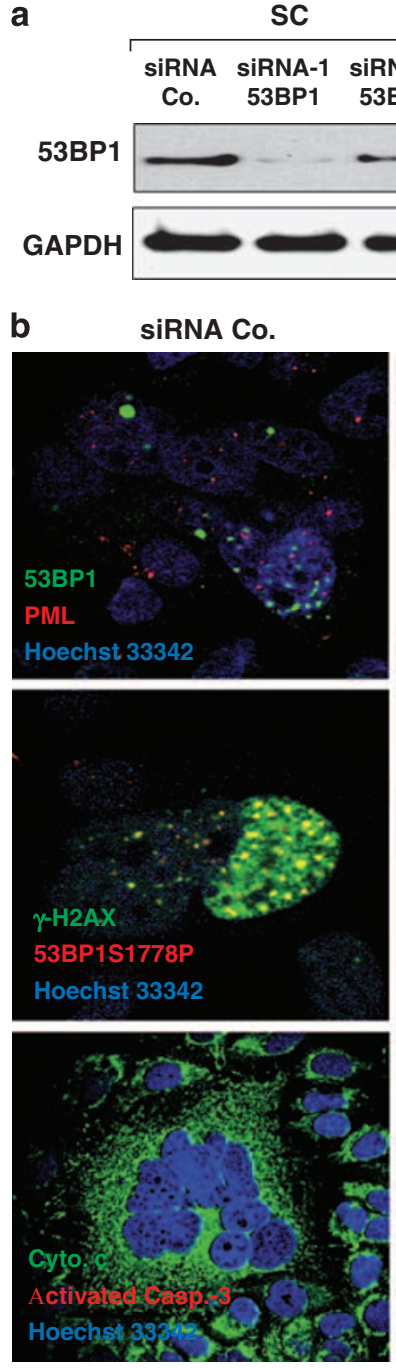
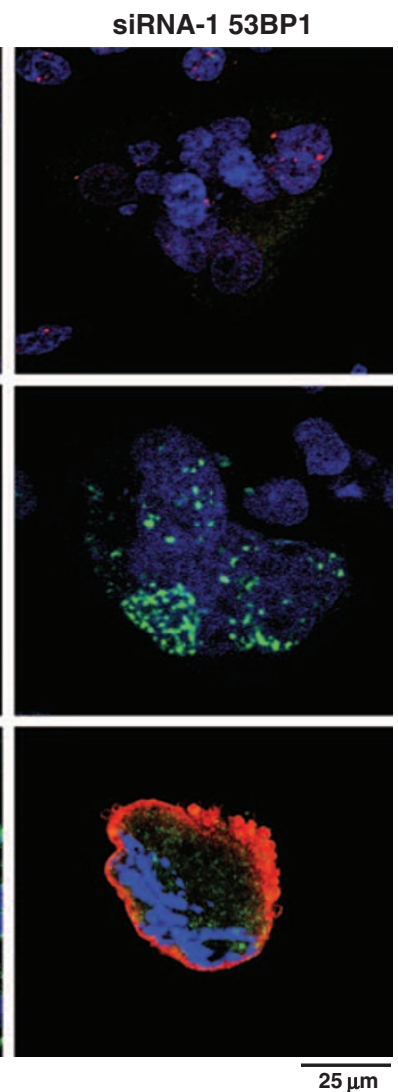

C

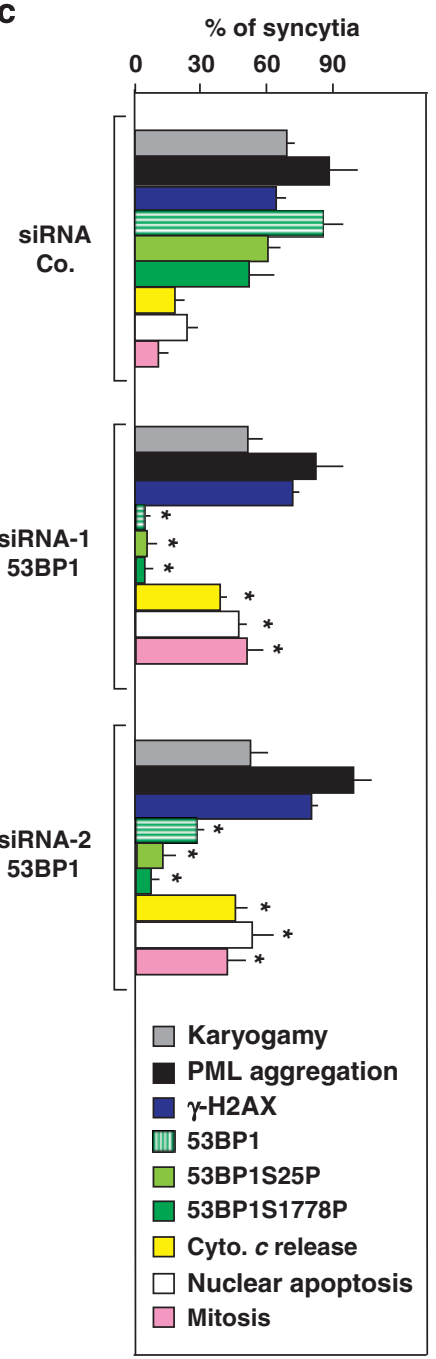

Figure 4 53BP1 depletion induces syncytial cell death through an increase in mitoses. (a-c) HeLa CD4 and HeLa Env cells were separately transfected with 53BP1-specific siRNAs, and $48 \mathrm{~h}$ later the cells were cocultured for further $36 \mathrm{~h}$, lysed and subjected to the immunodetection of 53BP1 and GAPDH (a). Representative karyogamic syncytia transfected during $36 \mathrm{~h}$ with specific siRNA against 53BP1 and stained with antibodies specific for 53BP1, 53BP1S1778P, PML, $\gamma$-H2AX, cytochrome $c$ (Cyto. c) or activated caspase-3 are shown (b). Note that 53BP1 depletion triggers cytochrome $c$ release and chromatin condensation on Env-elicited syncytia. Effect of 53BP1 depletion on the pro-apoptotic signaling pathway induced by HIV-1 envelope and on mitosis (c). The frequency of syncytia showing nuclear aggregation of PML or 53BP1, phosphorylation events 53BP1S25P, 53BP1S1778P, ATMS1981P, $\gamma$-H2AX, cytochrome $c$ release or nuclear apoptosis (chromatin condensation) was assessed using immunofluorescence microscopy. Karyogamy (KG) and mitosis were determined using Hoechst 33342 staining $(X \pm$ S.D., $n=5$ )

the percentage of PBMC that were positive for phospho-53BP1 dropped (Figure 6e), underscoring the relationship between HIV-1 infection and 53BP1 phosphorylation.

Concluding remarks. In this study we provide evidence that 53BP1, a protein involved in the DDR, can be activated in the course of HIV-1 infection, including in the brain and in lymphatic tissues, correlating with viral load. Previous reports have underscored that HIV-1 induces DDR, either by retroviral insertion into the host genome (which induces double-strand breaks) ${ }^{31}$ or by the action of the accessory protein, viral protein $\mathrm{R}$ ( $\mathrm{Vpr}$, which can bind to chromatin). ${ }^{32}$ In this study we show that HIV-1 may activate the DDR, including 53BP1 aggregation and phosphorylation, by an additional mechanism, which is syncytium formation. Indeed, the action of fusogenic Env can stimulate DDR in the absence of the retrovirus and Vpr. This DDR is linked to the advent of $\mathrm{KG}$, at least in vitro. Although the data obtained on patient tissues do not prove that 53BP1 activation has occurred as a by-product of syncytium formation, the fact that 53BP1 phosphorylation occurs within syncytia strongly suggest that this might contribute to AIDS pathogenesis.

Although ATM is clearly required for phosphorylation of 53BP1 (and H2AX), it is dispensable for 53BP1 aggregation, indicating that 53BP1 can interact with DNA in the absence of phosphorylated $\mathrm{H} 2 \mathrm{AX}$, at least in karyogamic syncytia. Moreover, the effects of ATM inhibition are very different 
a

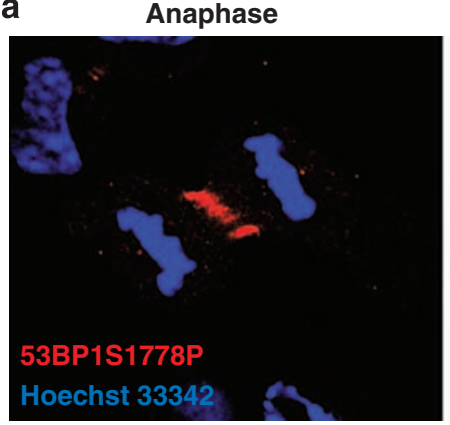

b siRNA Co., Pre-karyogamy

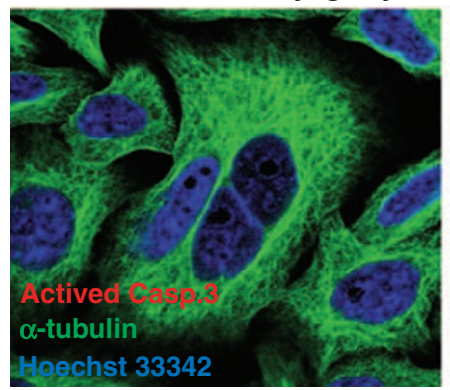

siRNA-1 p53BP1., Metaphase

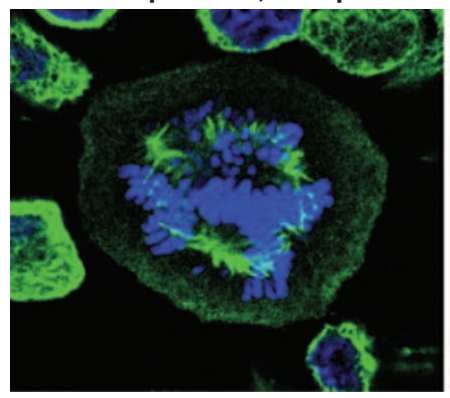

C siRNA-1 p53BP1., Metaphase

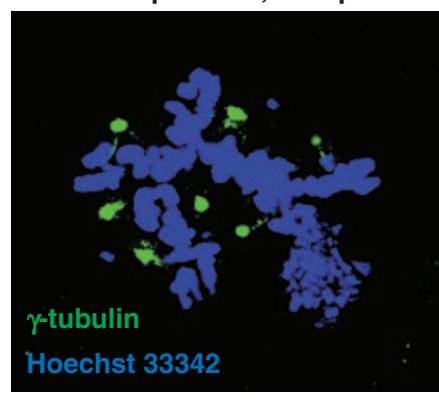

$12 \mu \mathrm{m}$
Telophase

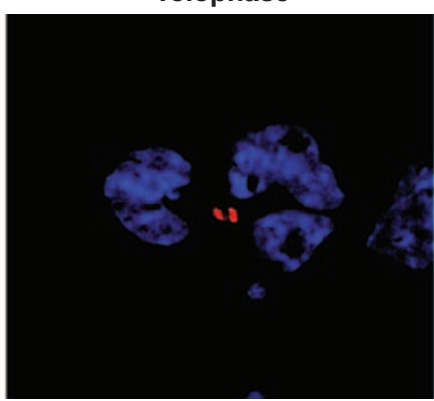

siRNA Co., Karyogamy

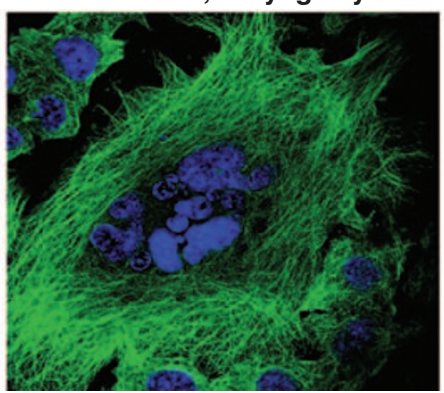

siRNA-1 p53BP1., Telophase

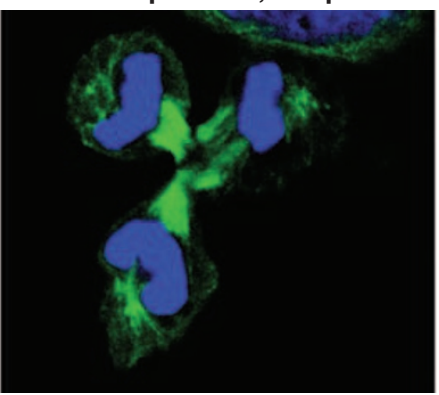

d

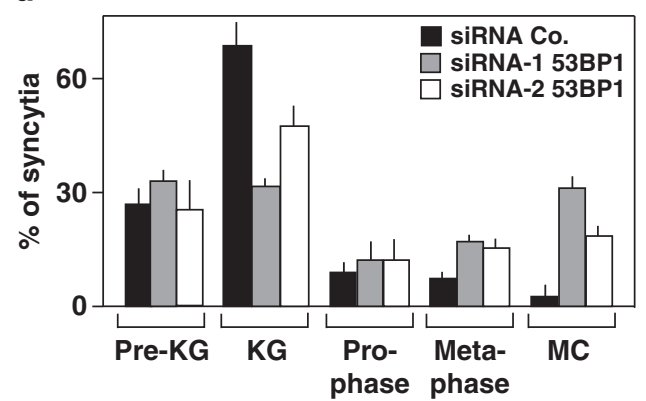

Cytokinesis

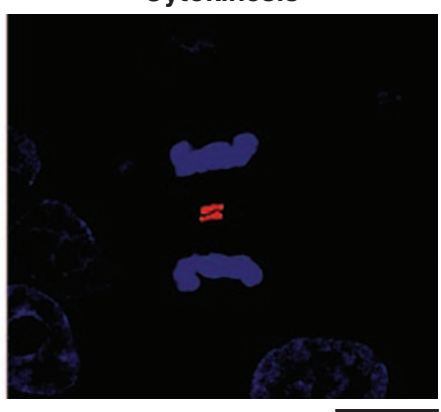

$25 \mu \mathrm{m}$

siRNA-1 p53BP1, Prophase

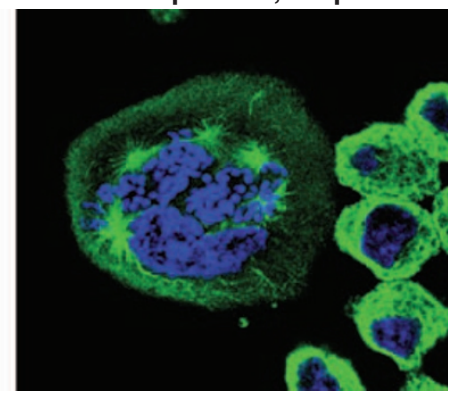

siRNA-1 p53BP1., M. catastrophe

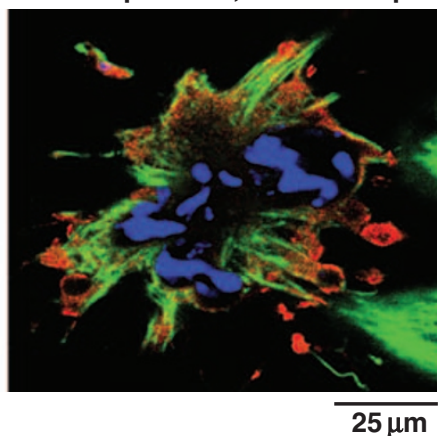

e

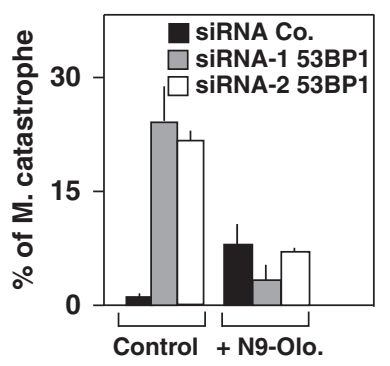

Figure 5 53BP1 knockdown induces mitotic catastrophe on HIV-1 Env-elicited syncytia. (a) Transient phosphorylation of 53BP1 on serine 1778 (53BP1S1778P) during normal mitosis. Detection of 53BP1S1778P during normal anaphase, normal telophase and normal cytokinesis using immunofluorescence microscopy. (b) Depletion of 53BP1 triggers abnormal mitosis and mitotic catastrophe of HIV-1 Env-elicited syncytia. HeLa CD4 and HeLa Env cells were separately transfected for 48 h with 53BP1specific siRNAs. Syncytia arising from the coculture of these cells for $36 \mathrm{~h}$ were fixed and stained with specific antibody against $\alpha$-tubulin and activated caspase-3 for immunofluorescence microscopy. Representative prekaryogamic and karyogamic syncytia, prophase, aberrant metaphase, telophase and mitotic catastrophe are shown. (c) Knockdown of 53BP1 leads to multipolar metaphases with multiple centrosomes. Cells were fixed and stained with antibody against $\gamma$-tubulin for immunofluorescence microscopy. Representative aberrant metaphase revealing numerous centrosomes is shown. (d) Quantification of different mitotic stages and mitotic catastrophe induced by 53BP1 silencing was determined (X \pm S.D., $n=3$ ). (e) Inhibition of syncytial mitotic catastrophe by N9-isopropyl-olomoucine. HeLa CD4 and HeLa Env cells were separately transfected for $48 \mathrm{~h}$ with 53BP1-specific siRNAs, and syncytia arising from the coculture of cells for $36 \mathrm{~h}$ were then incubated with $10 \mu \mathrm{M}$ of N9-isopropyl-olomoucine (N9-Olo). Cells were fixed and stained with specific antibodies against $\alpha$-tubulin and activated caspase-3 for immunofluorescence microscopy. The effects of N9- isopropyl-olomoucine on mitotic catastrophe induced by 53BP1 knockdown were determined (X \pm S.D., $n=3$ ) 
a

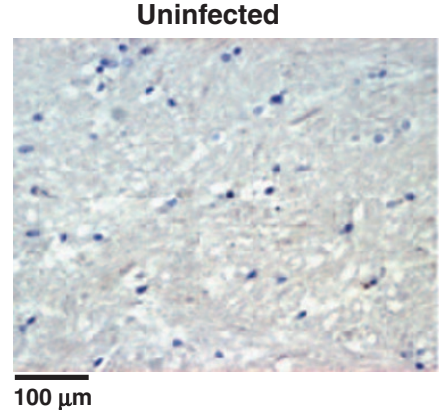

b

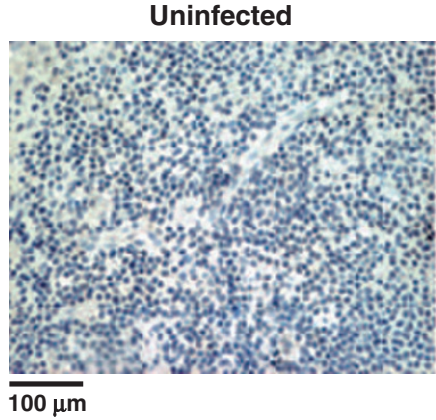

C
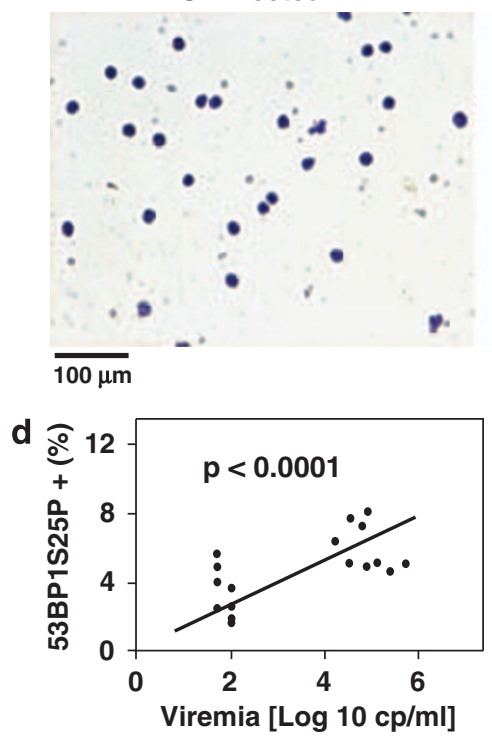

HIV-1 infected
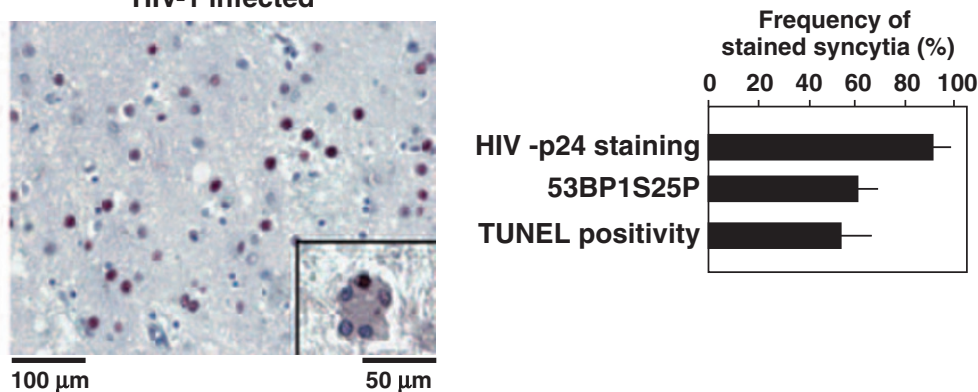

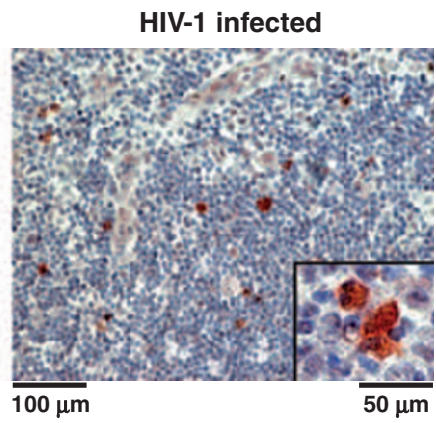

HIV-1 infected

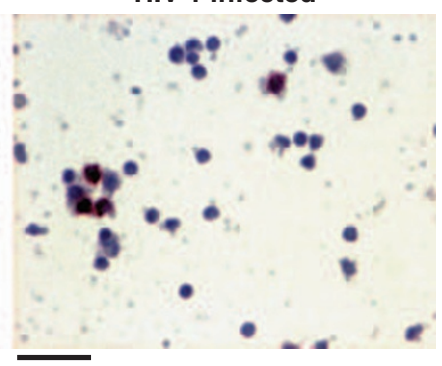

$\overline{100 \mu \mathrm{m}}$

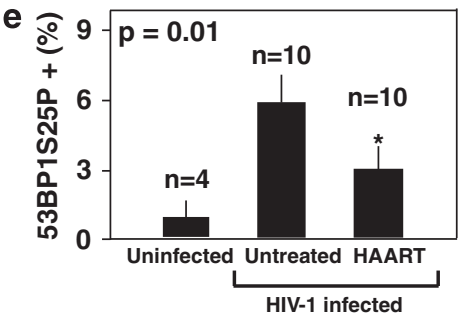

Figure 6 53BP1 phosphorylation in vivo, in HIV-1-infected patients. (a) Phosphorylation of 53BP1 on serine 25 in syncytia detectable in frontal cortex from patients with HIV-1-associated encephalitis (HAE). 53BP1S25P phosphorylations were visualized using immunohistochemistry on histological sections from control patients or from untreated HIV-1 carriers with HAE but without opportunistic infection. The insert shows labeled giant multinuclear cells. The percentage of syncytia (X \pm S.E.M.) staining positively for 53BP1S25P amounted to $58 \pm 9$, as determined for six different HIV-1 carriers. (b) 53BP1S25P phosphorylation in lymph nodes from controls and untreated HIV-1 carriers. The insert reveals bonafide labeled syncytia. (c) 53BP1S25P in PBMC derived from representative HIV-1-infected patients or healthy donors (Co.). Immunoperoxidase stainings are shown. (d, e) Correlation between 53BP1S25P, viral status and HAART treatment. PBMCs from untreated HIV-1-infected patients were subjected to 53BP1S25P staining and the values were plotted against the number of viral particles in the serum. The $P$-values refer to the correlation coefficients (d). A cohort of HIV-1- donors, untreated HIV-1 carriers and HAART-treated subjects with undetectable viremia were analyzed for 53BP1S25P (e)

from those obtained by depletion of 53BP1. The pharmacological inhibition of ATM, its homozygous mutation (in A-T patients) or its knockdown, all result in a clear inhibition of syncytial apoptosis. In strict contrast, we found that 53BP1 is unique insofar that it is the first DNA damage-related protein that acts as a negative regulator of syncytial demise. 53BP1 knockdown enhanced syncytial apoptosis through a mechanism that is linked to an increased progression into mitosis, followed by death during or shortly after mitosis. In normal circumstances, mitotic catastrophe is a rare event in Env-elicited syncytia. ${ }^{33}$ Usually, such syncytia progress into the prophase of the cell cycle and hence dismantle the nuclear envelope after the phosphorylation of lamin B by Cdk1. ${ }^{34}$ Karyogamy can then ensue because of the absence of the 
barrier of the nuclear envelope. After KG, most syncytia arrest cell-cycle advancement at the level of the prophase, unless checkpoint kinases are inhibited ${ }^{9}$ or, as shown in this study, 53BP1 is depleted. Accordingly, 53BP1 knockdown is only lethal when the cells are allowed to progress into mitosis, underscoring the intimate link between apoptosis and the frustrated attempt of multiastral division that precedes cellular demise.

So far, 53BP1 is considered as a scaffold protein that is devoid of any enzymatic activity, and hence is unlikely to constitute a pharmacological target. However, 53BP1 is affected in its activity by enzymes, such as the ubiquitin ligase RNF168, ${ }^{35}$ and it will be important to study whether the inhibition of such upstream factors will suppress syncytial apoptosis (as this has been found for ATM inhibition) or rather exacerbate synctial apoptosis. On theoretical grounds, agents that induce the selective death of HIV-1-elicited syncytia might lead to the elimination of viral reservoirs and hence constitute a complement to current antiretroviral therapies. This intriguing possibility warrants further exploration in the future.

\section{Materials and Methods}

Antibodies, plasmids and reagents. Monoclonal antibodies for detection of 53BP1, and anti- Cyto. $c$ were purchased from Becton Dickinson (Franklin lakes, $\mathrm{NJ}$, USA). Polyclonal rabbit antibody against 53BP1S25P was obtained from Novus Biologicals (Littleton, CO, USA). The polyclonal rabbit antibodies used for the detection of the activated forms of caspase-3 or 53BP1S1778P were from Cell Signaling Technology (Danvers, MA, USA). Monoclonal antibodies against ATM, ATM phosphorylated on serine 1981 (ATMS1981P), H2AX and $\gamma$-H2AX were obtained from Upstate (Lake Placid, NY, USA). The plasmid for Baculovirus p35 was provided by Dr. Guy Salvesen (Burnham Institute, La Jolla, CA, USA). DN mutant plasmids for Cdk1, IKSR, DN p53 (H175) and DN p38 MAPK were previously described. ${ }^{2}$ Where indicated, cells were treated with roscovitin and SB203580 (Calbiochem-Novabiochem, La Jolla, CA, USA), N9-isopropylolomoucine (Alexis Biochemicals, Lausen, Germany), AMD3100, rapamycin (all from Sigma-Aldrich (Saint-Louis, MO, USA)), pifithrin- $\alpha$ and Z-VAD-fmk (all from Bachem (Weil am Rhein, Germany)).

Cell lines, cell culture and transfection. HeLa cells stably transfected with the Env gene of HIV-1 LAI/IIIB (HeLa Env) and HeLa cells transfected with CD4 (HeLa CD4) were cultured alone or together in a 1:1 ratio in Dulbecco's modified Eagle's medium supplemented with $10 \% \mathrm{FCS}, 2 \mathrm{mM}$ L-glutamine and penicillin/ streptomycin (Invitrogen, Carlsbad, CA, USA) in the absence or presence of $1 \mu \mathrm{M}$

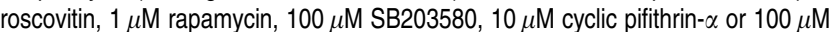
Z-VAD-fmk during indicated times. Transfections of plasmids were performed with lipofectamine 2000 (Invitrogen), $24 \mathrm{~h}$ before cell fusion.

Immunoblots and immunofluorescence. Total cellular proteins were extracted in $250 \mathrm{mM} \mathrm{NaCl}$-containing lysis buffer $(250 \mathrm{mM} \mathrm{NaCl}, 0,1 \% \mathrm{NP} 40,5 \mathrm{mM}$ EDTA $10 \mathrm{mM}$ Na3VO4, $10 \mathrm{mM} \mathrm{NaF}, 5 \mathrm{mM}$ DTT, $3 \mathrm{mM}$ Na4P2O7 and protease inhibitor cocktail). Proteins extracts $(30 \mu \mathrm{g})$ were run on $4-8 \%$ SDS-PAGE and transferred at $4^{\circ} \mathrm{C}$ onto nitrocellulose membrane. After blocking, membranes were incubated with primary antibody against 53BP1 at room temperature for $1 \mathrm{~h}$ and $30 \mathrm{~min}$. Then, horse radish peroxidase conjugated goat anti-mouse (Southern Biotechnology, Birmingham, AL, USA) antibodies were incubated for $1 \mathrm{~h}$ and revealed with the enhanced ECL detection system. For immunofluorescence, cells were fixed in $4 \%$ paraformaldehyde/ phosphate-buffered saline (PBS) for $20 \mathrm{~min}$, permeabilized in $0.1 \%$ SDS in PBS and incubated with FCS for $20 \mathrm{~min}$, as previously described. Then, indicated sera were used for immunodetection in PBS containing $1 \mathrm{mg} / \mathrm{ml} \mathrm{BSA}$ and revealed with goat anti-rabbit IgG conjugated to Alexa 488 (green) or Alexa 568 (red) fluorochromes from Invitrogen. To assess KG and nuclear apoptosis, cells were counterstained with Hoechst 33342 (Invitrogen). Proteins attached to damaged nuclear matrix were detected by immunofluorescence microscopy using the previously described procedure.
RNA interference. Published siRNAs specific for $A T M,{ }^{8} \mathrm{PML}^{13}{ }^{13}$ TopBP $1,{ }^{13}$ 53BP1(h53BP1.1: $5^{\prime}$-GAACGAGGAGACGGUAATAdTdT-3'25 or h53BP1.2: $5^{\prime}$-AA GAACGAGGAGACGGTAATAdTdT-3' $)^{14}$ were transfected using Oligofectamine (Invitrogen), according to the manufacturer's instructions.

Viral and pseudo-viral constructs. Viral stock of wild-type X4 HIV-1 was obtained after transfection of 293T with virus encoding plasmids as previously described. ${ }^{8,13}$

Patients. Axillary lymph node biopsies were obtained from healthy and HIV-1infected individuals (all males, mean age 36 years, with a plasma viral load $>105$ copies/ml). Plasma HIV-1 RNA levels were determined using the bDNA procedure (Versant HIV RNA 3.0; Bayer Diagnostics, Berkeley, CA, USA). Post-mortem frontal cortex sections were obtained from 17 brains of patients with HIV-1associated dementia (but lacking secondary infections) and three control brains obtained from uninfected control patients. PBMCs from two patients with ATM mutations and clinical signs of A-T (patient 1: male, 18 years, heterozygous for two truncating ATM mutations, $7792 \mathrm{C}>\mathrm{T}$ and $8283 \mathrm{delTC}$; patient 2: female, 30 years, homozygous for ATM mutation $9139 \mathrm{C}>\mathrm{T}$ ), as well as from healthy donors and HIVseropositive individuals were also obtained and isolated as described in the study by Perfettini et al. ${ }^{8}$ These samples were obtained with written informed consent in accordance with the National and European legal requirements, after approval by the institutional review board of the National Institute for Infectious Disease and the Medical Faculty of the University of Rome.

Immunohistochemical analysis. Paraffin embedded human tissue sections were deparaffinized, rehydrated and subjected to high-temperature antigen retrieval in $10 \mathrm{mM}$ sodium citrate buffer, $\mathrm{pH} \mathrm{6.0.} \mathrm{On} \mathrm{human} \mathrm{tissue} \mathrm{sections}$ and on fixed PBMCs, the endogenous peroxidase activity was blocked by $3 \% \mathrm{H}_{2} \mathrm{O}_{2}$. Rabbit antibody against phospho-53BP1 (Novus Biologicals) and biotinylated goat anti-rabbit IgG were incubated with tissue sections. Then, the immunoreaction product obtained with a preformed horseradish peroxidase-conjugated streptavidin (Biogenex, San Ramon, CA, USA) was revealed using aminoethylcarbazole (AEC) as chromogenic substrates and $0.01 \% \mathrm{H}_{2} \mathrm{O}_{2}$ (Biogenex). Sections were counterstained using Mayer's acid hemalum.

\section{Conflict of interest}

The authors declare no conflict of interest.

Acknowledgements. We thank the NIH AIDS Research and Reference Reagent Program (Bethesda, MD, USA) for reagents and Didier Métivier (INSERM U848, Villejuif, France) for technical help. This work has been supported by a special grant from LNC, as well as grants by ANRS, Sidaction and the European Commission (RIGHT, ACTIVE P53, ApoSys) (to GK) and Istituto Superiore di Sanità ( ${ }^{\circ}$ 40F60, Ricerca Corrente e Finalizzate 'Ministerio della Saluté', COFIN frim MIUR and AIRC).

1. Perfettini JL, Castedo M, Roumier T, Andreau K, Nardacci R, Piacentini $M$ et al. Mechanisms of apoptosis induction by the HIV-1 envelope. Cell Death Differ 2005; 12 (Suppl 1): 916-923.

2. Perfettini JL, Roumier T, Castedo M, Larochette N, Boya P, Raynal B et al. NF-kappaB and p53 are the dominant apoptosis-inducing transcription factors elicited by the HIV-1 envelope. J Exp Med 2004; 199: 629-640.

3. Garg H, Joshi A, Freed EO, Blumenthal R. Site-specific mutations in HIV-1 gp41 reveal a correlation between HIV-1-mediated bystander apoptosis and fusion/hemifusion. $J$ Biol Chem 2007; 282: 16899-16906.

4. Garg H, Blumenthal R. Role of HIV Gp41 mediated fusion/hemifusion in bystander apoptosis. Cell Mol Life Sci 2008; 65: 3134-3144.

5. Castedo M, Ferri KF, Blanco J, Roumier T, Larochette N, Barretina J et al. Human immunodeficiency virus 1 envelope glycoprotein complex-induced apoptosis involves mammalian target of rapamycin/FKBP12-rapamycin-associated protein-mediated p53 phosphorylation. J Exp Med 2001; 194: 1097-1110.

6. Castedo M, Roumier T, Blanco J, Ferri KF, Barretina J, Tintignac LA et al. Sequential involvement of Cdk1, mTOR and p53 in apoptosis induced by the HIV-1 envelope. EMBO J 2002; 21: 4070-4080.

7. Perfettini JL, Castedo M, Nardacci R, Ciccosanti F, Boya P, Roumier T et al. Essential role of p53 phosphorylation by p38 MAPK in apoptosis induction by the HIV-1 envelope. J Exp Med 2005; 201: 279-289. 
8. Perfettini JL, Nardacci R, Bourouba M, Subra F, Gros L, Seror C et al. Critical involvement of the ATM-dependent DNA damage response in the apoptotic demise of HIV-1-elicited syncytia. PLOS ONE 2008; 3: e2458.

9. Seror C, Raza SQ, Brottes F, Subra F, Piacentini M, Perfettini JL et al. Pro-apoptotic function of checkpoint kinase-2 in syncytia elicited by the HIV-1 envelope. Cell Cycle 2009; 8: $438-442$.

10. Castedo M, Perfettini JL, Piacentini M, Kroemer G. p53-A pro-apoptotic signal transducer involved in AIDS. Biochem Biophys Res Commun 2005; 331: 701-706.

11. Ferri KF, Jacotot $\mathrm{E}$, Blanco J, Este JA, Zamzami N, Susin SA et al. Apoptosis control in syncytia induced by the HIV type 1-envelope glycoprotein complex: role of mitochondria and caspases. J Exp Med 2000; 192: 1081-1092.

12. Roumier T, Castedo M, Perfettini JL, Andreau K, Metivier D, Zamzami N et al. Mitochondrion-dependent caspase activation by the HIV-1 envelope. Biochem Pharmacol 2003; 66: 1321-1329.

13. Perfettini JL, Nardacci R, Seror C, Bourouba M, Subra F, Gros L et al. The tumor suppressor protein PML controls apoptosis induced by the HIV-1 envelope. Cell Death Differ 2009; 16: 298-311.

14. Wang B, Matsuoka S, Carpenter PB, Elledge SJ. 53BP1, a mediator of the DNA damage checkpoint. Science 2002; 298: 1435-1438.

15. Rappold I, Iwabuchi K, Date T, Chen J. Tumor suppressor p53 binding protein 1 (53BP1) is involved in DNA damage-signaling pathways. J Cell Biol 2001; 153: 613-620.

16. Ward IM, Minn K, van Deursen J, Chen J. p53 Binding protein 53BP1 is required for DNA damage responses and tumor suppression in mice. Mol Cell Biol 2003; 23: 2556-2563.

17. Difilippantonio S, Gapud E, Wong N, Huang CY, Mahowald G, Chen HT et al. 53BP1 facilitates long-range DNA end-joining during V(D)J recombination. Nature 2008; 456 529-533.

18. Dimitrova N, Chen YC, Spector DL, de Lange T. 53BP1 promotes non-homologous end joining of telomeres by increasing chromatin mobility. Nature 2008; 456: 524-528.

19. Ward IM, Minn K, Jorda KG, Chen J. Accumulation of checkpoint protein 53BP1 at DNA breaks involves its binding to phosphorylated histone H2AX. J Biol Chem 2003; 278: 19579-19582.

20. Zgheib O, Pataky K, Brugger J, Halazonetis TD. An oligomerized 53BP1 tudor domain suffices for recognition of DNA double-strand breaks. Mol Cell Biol 2009; 29: 1050-1058.

21. Schultz LB, Chehab NH, Malikzay A, Halazonetis TD. p53 binding protein 1 (53BP1) is an early participant in the cellular response to DNA double-strand breaks. J Cell Biol 2000; 151: $1381-1390$
22. Iwabuchi K, Basu BP, Kysela B, Kurihara T, Shibata M, Guan D et al. Potential role for 53BP1 in DNA end-joining repair through direct interaction with DNA. J Biol Chem 2003 278: 36487-36495.

23. Lukas C, Falck J, Bartkova J, Bartek J, Lukas J. Distinct spatiotemporal dynamics of mammalian checkpoint regulators induced by DNA damage. Nat Cell Biol 2003; 5 : 255-260.

24. Anderson L, Henderson C, Adachi Y. Phosphorylation and rapid relocalization of 53BP1 to nuclear foci upon DNA damage. Mol Cell Biol 2001; 21: 1719-1729.

25. DiTullio Jr RA, Mochan TA, Venere M, Bartkova J, Sehested M, Bartek J et al. 53BP1 functions in an ATM-dependent checkpoint pathway that is constitutively activated in human cancer. Nat Cell Biol 2002; 4: 998-1002.

26. Kang Y, Lee JH, Hoan NN, Sohn HM, Chang IY, You HJ. Protein phosphatase 5 regulates the function of 53BP1 after neocarzinostatin-induced DNA damage. J Biol Chem 2009 284: 9845-9853.

27. Jullien D, Vagnarelli $P$, Earnshaw WC, Adachi Y. Kinetochore localisation of the DNA damage response component 53BP1 during mitosis. J Cell Sci 2002; 115: 71-79.

28. Ferri KF, Jacotot $\mathrm{E}$, Geuskens M, Kroemer G. Apoptosis and karyogamy in syncytia induced by the HIV-1-envelope glycoprotein complex. Cell Death Differ 2000; 7: 1137-1139.

29. Xia Z, Morales JC, Dunphy WG, Carpenter PB. Negative cell cycle regulation and DNA damage-inducible phosphorylation of the BRCT protein 53BP1. J Biol Chem 2001; 276 2708-2718.

30. Jowsey P, Morrice NA, Hastie CJ, McLauchlan H, Toth R, Rouse J. Characterisation of the sites of DNA damage-induced 53BP1 phosphorylation catalysed by ATM and ATR. DNA Repair (Amst) 2007; 6: 1536-1544.

31. Skalka AM, Katz RA. Retroviral DNA integration and the DNA damage response. Cell Death Differ 2005; 12 (Suppl 1): 971-978.

32. Lai M, Zimmerman ES, Planelles V, Chen J. Activation of the ATR pathway by human immunodeficiency virus type $1 \mathrm{Vpr}$ involves its direct binding to chromatin in vivo. J Virol 2005; 79: 15443-15451.

33. Castedo M, Perfettini JL, Roumier T, Andreau K, Medema R, Kroemer G. Cell death by mitotic catastrophe: a molecular definition. Oncogene 2004; 23: 2825-2837.

34. Castedo M, Perfettini JL, Roumier T, Kroemer G. Cyclin-dependent kinase-1: linking apoptosis to cell cycle and mitotic catastrophe. Cell Death Differ 2002; 9: 1287-1293.

35. Sakasai R, Tibbetts R. RNF8-dependent and RNF8-independent regulation of 53BP1 in response to DNA damage. J Biol Chem 2008; 283: 13549-13555.

Supplementary Information accompanies the paper on Cell Death and Differentiation website (http://www.nature.com/cdd) 